\title{
VISTORIA PREDIAL EM EDIFÍCIO RESIDENCIAL INTERDITADO NA CIDADE DE SOBRAL, CEARÁ
}

\author{
ARAÚJO, LUCAS EMANUEL FERNANDES \\ Acadêmico de Engenharia Civil \\ Universidade Estadual Vale do Acaraú \\ Ceará; Brasil \\ lucase.fernandes@outlook.com
}

\author{
Engenheira Civil, Prof ${ }^{a}$ \\ Universidade Estadual Vale do Acaraú \\ Ceará; Brasil \\ kelvyamoreira@gmail.com
}

MOREIRA, KELVYA MARIA VASCONCELOS

\author{
CARVALHO, FELIPE MELO \\ Acadêmico de Engenharia Civil \\ Universidade Estadual Vale do Acaraú \\ Ceará; Brasil \\ felipe.melo.7717@gmail.com
}

\author{
SALES, JUSCELINO CHAVES \\ Engenheiro Mecânico, Prof \\ Universidade Estadual Vale do Acaraú \\ Ceará; Brasil \\ juscelinochaves@hotmail.com
}

\begin{abstract}
RESUMO
Diante dos casos recentes de colapsos totais e parciais de edificações ocorridos na cidade de Fortaleza, Ceará, objetivou-se analisar a situação atual de um edifício residencial localizado na cidade de Sobral, Ceará, interditado por instituições fiscalizadoras no ano de 2012 após vistoria. Tal edificação foi construída em 1981 e não passou por intervenções técnicas de manutenção periódica até a interdição. O relatório final apontou risco iminente de colapso estrutural decorrente de infiltrações que degradaram a integridade da estrutura. Até o momento, a edificação não foi demolida tampouco possui sistema de escoramento ou isolamento externo da área edificada. Diante da gravidade, essa pesquisa visou realizar uma vistoria predial para analisar a magnitude das manifestações patológicas incidentes no prédio bem como a ocorrência de novas anomalias após o período de interdição, utilizando-se de ensaios de caráter não destrutivos, para verificar a possibilidade de ocorrer colapso estrutural.
\end{abstract}

Palavras-chave: vistoria predial, manifestações patológicas, interdição, colapso estrutural.

\section{ABSTRACT}

Given the recent cases of total and partial collapse of buildings occurred in the city of Fortaleza, Ceará, the objective was to analyze the current situation of a residential building located in the city of Sobral, Ceará, interdicted by inspection institutions in 2012 after inspection. This building was built in 1981 and was not periodically maintained until the ban. The final report indicates an imminent risk of structured collapse due to infiltrations that degrade the integrity of the structure. Until now, the building has not been demolished nor has a shoring system or external isolation of the built area. This research aimed to perform a building analysis to verify the magnitude of the pathological manifestations incident in the building and the occurrence of new anomalies after the interdiction period to verify the possibility of structural collapse. For this, we used non-destructive tests.

Keywords: building analysis, pathological manifestations, interdiction, structural collapse.

\section{INTRODUÇÃO}

Casos de tragédias referentes a colapso de edificações estão se apresentando com maior frequência no cenário nacional, causando prejuízos financeiros e, principalmente, fatalidades que proporcionam sequelas à sociedade, fazendo com que cresça a conscientização sobre a importância da inspeção predial. Casos como o colapso ocorrido na comunidade de Muzema, no Rio de Janeiro, em 2019, que, por se tratar de edificações irregulares que não passaram por vistorias técnicas nem reparos estruturais durante a vida útil, resultou no óbito de 24 pessoas. No mesmo ano, um edifício de sete pavimentos, o Residencial Andréa, localizado na cidade de Fortaleza, Ceará, desmoronou. Uma análise realizada no mês anterior ao do desabamento apresentou 135 pontos críticos na estrutura. $\mathrm{O}$ desabamento ocorreu no primeiro dia do reparo da estrutura do pilotis e resultou em 9 vítimas fatais. Além destes casos existe uma série de relatos de acidentes e prejuízos econômicos devido a falta de manutenção, desgaste dos imóveis por mau uso, pois não passam por inspeções regularmente, além de escolha de intervenção técnica não adequada.

Dada a relevância do tema, cresce a conscientização sobre a importânica da inspeção predial e é necessário apresentar metodologias de análise para a perícia de imóveis que se encontram em estado crítico e avaliar a evolução das 
manifestações presentes. O objetivo deste trabalho é analisar a situação atual de um edifício residencial localizado na cidade de Sobral, Ceará. Ele foi interditado pelo poder público no ano de 2012 após vistorias do Corpo de Bombeiros e da Defesa Civil que constataram risco iminente de colapso estrutural decorrente de infiltrações, geração de chorume no poço do elevador e falhas de projetos que afetaram a integridade da estrutura. Considerando essa conjuntura, Farias (2019) afirma que o trabalho de diagnóstico das manifestações patológicas se mostra como uma área em desenvolvimento na engenharia, que precisa de atenção especial na busca por estruturas mais sustentáveis e seguras.

Diante da gravidade da situação, esta pesquisa visou realizar uma vistoria predial para analisar a magnitude das manifestações patológicas incidentes no prédio bem como a ocorrência de novas anomalias após este período de interdição, utilizando-se, para isso, procedimentos necessários para a realização de inspeção predial, com a elaboração de um check-list que contém um roteiro prático fundamentado nas normas pertinentes. A ABECE (2005) reforça que o check-list tem como objetivo minimizar os riscos, indicar as formas de preservação, a integridade dos edifícios com mais de dez anos construídos sob técnicas e normas não atuais, com consequente revalorização do patrimônio.

Foi aplicada uma matriz GUT (Gravidade - Urgência - Tendência) como forma de estabelecer as prioridades para a solução dos problemas. Essa metodologia auxiliou para análise do check-list como complemento para a mensuração da atual situação do edifício. Também foi realizado ensaio de caráter não destrutivo através da aplicação do método da Velocidade de Propagação do Pulso Ultrassônico (VPU) e ensaio semi-destrutivo de carbonatação, ambos realizados em vigas e pilares que apresentaram pontos críticos mais relevantes para o estudo a fim de analisar se há a possibilidade de ocorrer colapso estrutural.

\section{REFERENCIAL TEÓRICO}

Segundo o IBAPE/SP (2017), inspeção predial é a análise isolada ou combinada das condições técnicas, de uso e de manutenção da edificação. Para a realização apropriada de uma inspeção predial o check-list é imprescindível para a identificação de anomalias presentes em uma estrutura. O check-list deve ser um instrumento de detalhamento e observação dos tópicos a serem inspecionados, representando assim um cronograma de fiscalização.

O IBAPE/SP (2017), em sua norma para a inspeção predial, considera que se deve incluir em um check-list os seguintes sistemas construtivos e elementos: estrutura, impermeabilização, instalações elétricas e hidráulicas, revestimento externo e interno, esquadrias, elevadores, climatização, exaustão mecânica, ventilação, coberturas, telhados, combate a incêndio e SPDA. É importante salientar que a inspeção em campo deve ser acompanhada por um registro fotográfico com o objetivo de constatar as condições do edifício, representando os aspectos mais relevantes destacados no cronograma de vistorias.

Uma das ferramentas utilizadas para a priorização na resolução de problemas e análise de inspeção predial é a matriz de gravidade, urgência e tendência (GUT). A análise GUT é muito utilizada naquelas questões em que é preciso de uma orientação para tomar decisões complexas e que exigem a análise de vários problemas (CAMARGO, 2018).

Proposta como uma ferramenta utilizada para definir prioridades dadas as diversas alternativas de ação, a matriz GUT responde racionalmente às questões como: "O que deve ser feito primeiro?" ou "Por onde começar?". A fim de responder estas perguntas, a ferramenta tem como objetivo ordenar a importância das ações, levando em consideração a gravidade, a urgência e a tendência do fenômeno, de forma a escolher a tomada de decisão mais favorável e menos prejudicial à situação (Tabelas 01 a 03) (MEIRELES, 2001).

Tabela 01: Detalhamento do grau de gravidade da matriz GUT.

\begin{tabular}{|c|c|c|}
\hline GRAU & GRAVIDADE & PESO \\
\hline Total & Perda de vidas humanas, do meio ambiente ou do próprio edifício & 10 \\
\hline Alta & Ferimentos em pessoas, danos ao meio ambiente ou ao edifício & 8 \\
\hline Média & Desconforto, deterioração do meio ambiente ou do edifício & 6 \\
\hline Baixa & Pequenos incômodos ou pequenos prejuízos financeiros & 3 \\
\hline Nenhuma & & 1 \\
\hline
\end{tabular}

Fonte: Meireles, 2001. 
Tabela 02: Detalhamento do grau de urgência da matriz GUT.

\begin{tabular}{|c|c|c|}
\hline GRAU & URGÊNCIA & PESO \\
\hline Total & Evento de ocorrência & 10 \\
\hline Alta & Evento prestes a ocorrer & 8 \\
\hline Média & Evento prognosticado em breve & 6 \\
\hline Baixa & Evento prognosticado para adiante & 3 \\
\hline Nenhuma & Evento imprevisto & 1 \\
\hline
\end{tabular}

Fonte: Meireles, 2001.

Tabela 03: Detalhamento do grau de tendência da matriz GUT.

\begin{tabular}{|c|c|c|}
\hline GRAU & TENDÊNCIA & PESO \\
\hline Total & Evolução imediata & 10 \\
\hline Alta & Evolução em curto prazo & 8 \\
\hline Média & Evolução em médio prazo & 6 \\
\hline Baixa & Evolução em longo prazo & 3 \\
\hline Nenhuma & Não vai evoluir & 1 \\
\hline
\end{tabular}

Fonte: Meireles, 2001.

A aplicação deste método pode ser dividida em 04 (quatro) etapas simples: (1) listar os problemas ou pontos de análise a serem sanados; (2) pontuar cada problema de acordo com os parâmetros estabelecidos; (3) classificar os problemas quanto a sua priorização, com base nos resultados na etapa anterior; e (4) tomar as decisões estratégicas cabíveis (SOTILLE, 2014).

Em uma inspeção predial, muitas vezes se requer investigações profundas sobre o estado de sua estrutura. Levando em consideração a preservação da integridade do elemento em estudo, o método deve ser o menos invasivo possível de modo a não ocasionar danos. Nesse sentido, existe uma gama de testes denominados ensaios não destrutivos (END) que se caracterizam como uma ferramenta para avaliação estrutural das construções, uma vez que causam pouco ou nenhum dano (ALVES, 2017).

O método de Velocidade de Propagação do Pulso Ultrassônico (VPU) consiste em medir o tempo de percurso das ondas longitudinais de pulso ultrassônico passando através do concreto. As ondas longitudinais com frequência que variam de $20 \mathrm{kHz}$ a $150 \mathrm{kHz}$ são as normalmente usadas. O tempo de percurso de partida inicial e recepção do pulso são medidas eletronicamente. O comprimento do percurso entre os transdutores, dividido pelo tempo de viagem, resulta na velocidade média de propagação de ondas (MEHTA; MONTEIRO, 2008).

Um método eficaz para a verificação da homogeneidade de um componente é colocar uma série de receptores ao longo da superfície de um elemento espesso de concreto. A transmissão envia pulsos e, de acordo com o princípio de Huygen, cada ponto de uma frente de onda se comporta como uma fonte isolada para a geração de ondas esféricas secundárias, criando uma série de frentes de ondas. Caso o material apresente uniformidade, os pontos indicarão uma linha de tendência obtida pelo gráfico tempo vs. distância; caso exista heterogeneidade, os pontos serão espaçados, o que desviará para a formação de uma linha (MEHTA; MONTEIRO, 2008).

Para a verificação da presença de camadas horizontais que se formam quando o concreto é exposto ao meio agressivo, Mehta e Monteiro (2008) explicam que se deve considerar uma camada com espessura $\mathrm{H}$ e uma velocidade de onda V1, que é menor que a velocidade V2 do concreto. Uma série de receptores é colocada na superfície. Primeiramente os receptores registrarão apenas a camada superior e a representação gráfica será a formação de uma linha reta com inclinação de 1/V1, mas a medida que se aumenta a distância a influência da camada inferior é percebida.

Diversos são os fatores que afetam a velocidade de onda no concreto, segundo Mehta e Monteiro (2008). Dentre eles, destacam-se:

a) Idade do concreto: à medida que a hidratação do cimento continua ao longo de sua vida útil, a porosidade diminui e as ondas se propagam mais rapidamente. 
b) Umidade do meio: os pulsos de onda se propagam rapidamente se o meio estiver em condições saturadas.

c) Agregado: a quantidade e o tipo de agregado influenciam na velocidade de onda, tendo em vista que o mesmo possui velocidades mais altas do que a pasta de cimento.

d) Microfissuração: forma-se quando o concreto é solicitado a tensões maiores que $50 \%$ da sua resistência à compressão.

e) Presença de armaduras: a presença de armaduras aumenta a velocidade de onda no concreto.

Além do ensaio de VPU, é preponderante a análise do desgaste das peças de concreto devido ao ataque de gases ácidos presentes tanto no meio urbano como industrial, tais como o gás carbono $\left(\mathrm{CO}_{2}\right)$, o gás sulfúrico $\left(\mathrm{H}_{2} \mathrm{~S}\right)$ e o gás dióxido de enxofre $\left(\mathrm{SO}_{2}\right)$, que podem provocar a carbonatação, reduzindo o seu $\mathrm{pH}$ e fragilizando a estrutura.

O contato dos gases ácidos do ambiente com a superfície da face exposta do concreto, chamado de carbonatação, é um processo que acontece naturalmente e que consiste na transformação de íons alcalinos do concreto em carbonatos (KAZMIERCZAK, 1996; NEVILLE, 1997; ROY, 1999).

O processo físico-químico da carbonatação se divide em diversas etapas, primeiramente o dióxido de carbono penetra nos poros ou fissuras do concreto e começa a diluir-se na umidade presente na estrutura, formando o composto chamado ácido carbônico $\left(\mathrm{H}_{2} \mathrm{CO}_{3}\right)$ (TOKUDOME, 2009).

Para a determinação da profundidade do processo de carbonatação no concreto utiliza-se uma solução de fenolftaleína. Esse indicador, em contato com a região carbonatada, não altera a cor do concreto, mas quando em contato com a região não carbonatada tem sua cor alterada para uma tonalidade vermelho carmim. Conforme citado, a carbonatação é definida por Molin (2007) como a reação físico-química entre os compostos hidratados do cimento e o $\mathrm{CO}_{2}$ podendo provocar a despassivação. Neste caso, a carbonatação provocará uma redução do pH que desestabilizará a camada passivante, podendo iniciar um processo de corrosão generalizada.

\section{METODOLOGIA}

A edificação em estudo foi construída em 1981, está localizada no centro da cidade de Sobral, a $220 \mathrm{~km}$ da capital cearense, em uma região bastante movimentada (Figura 01). Nas proximidades está localizada a rodoviária municipal. O edifício possui seis pavimentos e o térreo, com 6 apartamentos por andar, tendo acesso aos andares por elevador e escadas e possui estacionamento no térreo. Após a interdição, o pilotis do edifício foi utilizado irregularmente como locação de espaço para estacionamento provisório. Até a vistoria realizada pelas autoridades municipais em 2012 o imóvel não tinha passado por intervenções técnicas. Após oito anos da interdição, o imóvel não foi demolido tampouco passou por um processo de escoramento ou isolamento externo da área edificada.

Segundo o laudo técnico do Corpo de Bombeiros, emitido em 2012, o prédio não tinha condições de moradia, uma vez que a infiltração se tornou generalizada e havia comprometimento das fundações do poço do elevador devido ao chorume produzido da degradação dos resíduos domésticos depositados no local. O Ministério Público Estadual, então, determinou um prazo de 30 dias para que as 20 famílias desocupassem o prédio. Na época, o Corpo de Bombeiros ressaltou que, em virtude da situação do imóvel, medidas corretivas não seriam as mais recomendáveis, e sim a demolição. No entanto, os proprietários chegaram a realizar um levantamento orçamentário para a reforma, sendo necessário um investimento de $\mathrm{R} \$ 1,2$ milhão de reais para realizar a recuperação.

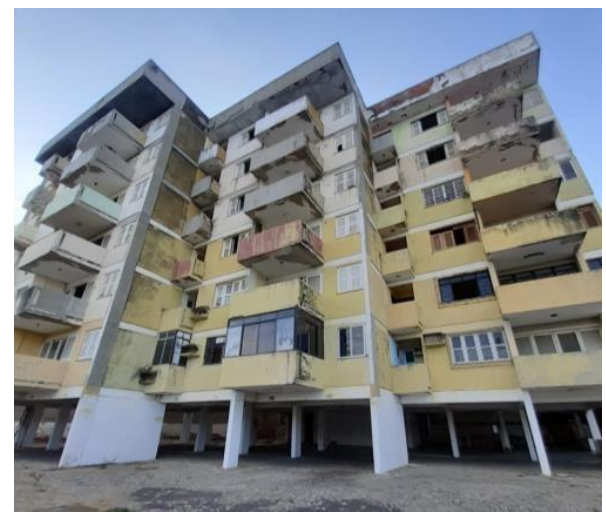

Figura 01: Edifício em estudo.

Fonte: Própria, 2019. 
A priori, realizou-se uma vistoria prévia para a identificação do imóvel e de possíveis pontos críticos da estrutura. Esta avaliação prévia consistiu na realização de um levantamento fotográfico e de uma entrevista com o ex-morador e síndico do imóvel a fim de auxiliar no preenchimento da ficha técnica para pontuar as possíveis manifestações patológicas e orientar na listagem dos pontos críticos (marcando a localização dos mesmos) e em observações pertinentes para a avaliação. O check-list utilizado na inspeção predial foi desenvolvido pelos pesquisadores Carvalho e Almeida (2017), cuja metodologia apresenta tópicos que servem de auxílio para entender a situação do imóvel.

Os tópicos avaliados na inspeção em campo foram: estrutura; vedação; revestimento do forro, da parede, do piso e da fachada; esquadria; impermeabilização; instalações hidrossanitárias; instalação de gás; instalação elétrica; mecanização dos elevadores, climatização, ventilação e exaustão mecânica, motor elétrico, bomba elétrica; cobertura; proteção de combate a incêndio; SPDA e áreas de lazer. As Figuras 02 a 08 apresentam os resultados de alguns tópicos avaliados seguindo a metogologia esboçada.

Utilizando-se da matriz GUT, foram identificados os pontos críticos e classificado o imóvel quanto ao grau de risco, mensurando as anomalias em uma escala de 0 a 10 quanto a gravidade, a urgência e a tendência, com base nas Tabelas 1 a 3. Como explicam Costa e Zancan (2012), para adequar o método à inspeção predial, deve-se atribuir pesos a cada anomalia existente e fazer a multiplicação entre eles obtendo-se, assim, o total de pontos.

Para a avaliação das vigas e pilares, foi utilizado um equipamento de ultrassom da marca PROCEQ®, modelo TICO, com transdutores de $54 \mathrm{kHz}$. Para a análise dos pilares, decidiu-se utilizar a abordagem semidireta, em que o transdutor transmissor e o transdutor receptor são posicionados perpendicularmente; e, para os ensaios nas vigas, utilizou-se a abordagem indireta, em que os transdutores ficaram com suas faces paralelas. Os transdutores são responsáveis por enviar e receber os pulsos mecânicos que irão viajar através do material e também transformar esses pulsos mecânicos em estímulos elétricos e vice-versa.

A realização do ensaio de VPU em vigas ocorreu primeiramente pela identificação dos elementos estruturais menos deteriorados e que tinham uma estrututa semelhante em projeto e dimensões, além de possuírem o mesmo carregamento, em que se encontrava em bom estado, para servir de controle tecnológico. A viga em análise (em mau estado) foi denominada de V1 e a viga de controle (menos deteriorada) denominada de CV1. Ambas estão localizadas no pilotis do imóvel.

A realização do ensaio de VPU nos pilares seguiu a mesma metodologia de escolha dos elementos estruturais ocorrido com as vigas. Os pilares em análise (em mau estado) foram denominados de P1 e o pilar de controle de $\mathrm{CP} 1$. Foram analisados 2 pilares de 3 pavimentos distintos (pilotis, primeiro e segundo andar).

O ensaio de carbonatação foi realizado em vigas, lajes e pilares pré-determinados na inspeção prévia, sendo a escolha decidida pelo grau de deterioração provocado pelo meio.

\section{RESULTADOS}

As Figuras 02 a 08 apresentam os resultados das análises das anomalias seguindo os critérios da matriz GUT.

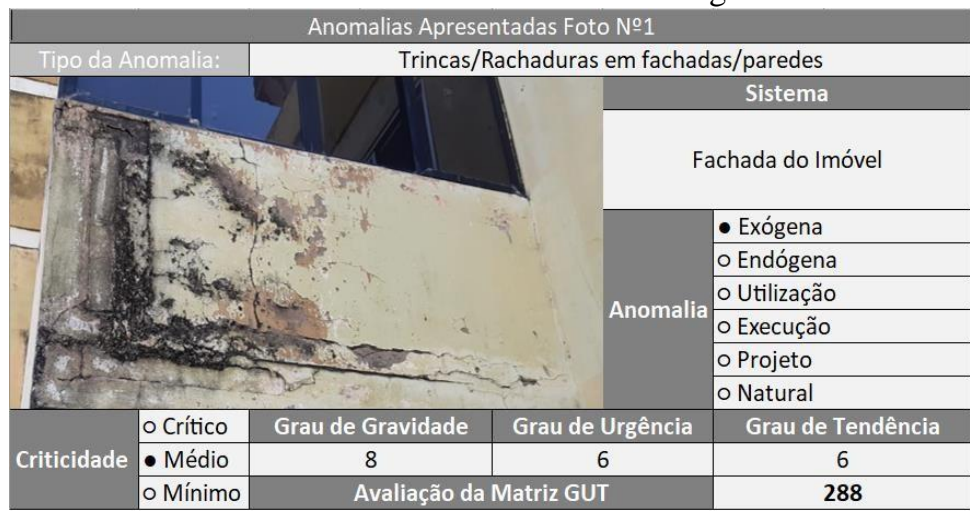

Figura 02: Avaliação das anomalias trincas/rachaduras em fachadas.

Fonte: Própria, 2019. 


\section{CBPAT 2020 \\ concersso ans \\ DE 15 A 17 DE ABRIL | FORTALEZA - CE}

ISBN 978-65-86819-05-2

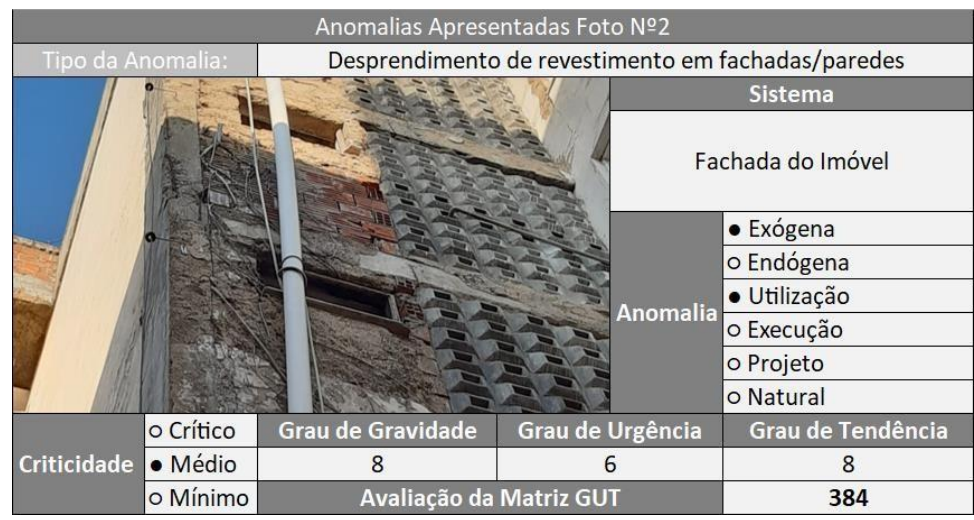

Figura 03: Avaliação das anomalias desprendimento de revestimento em fachada. Fonte: Própria, 2019.

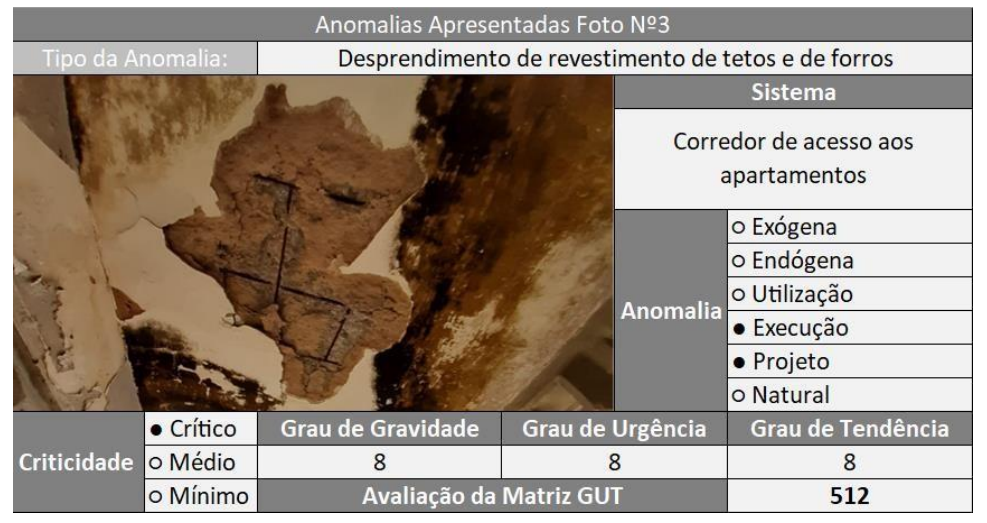

Figura 04: Avaliação das anomalias desprendimento de revestimento de tetos e forros. Fonte: Própria, 2019.

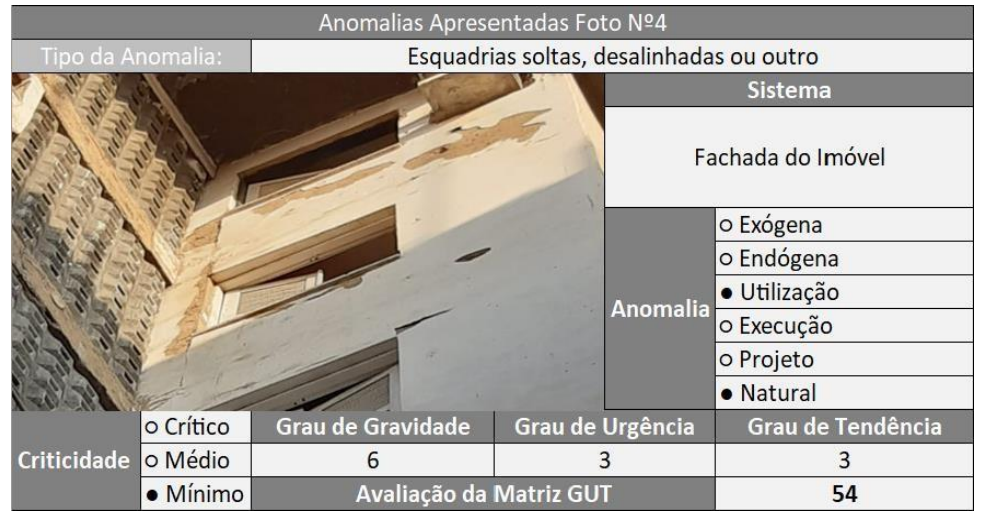

Figura 05: Avaliação de anomalias em esquadrias.

Fonte: Própria, 2019. 


\section{СВРAT 2020 \\ concerss b ous \\ DE 15 A 17 DE ABRIL | FORTALEZA - CE}

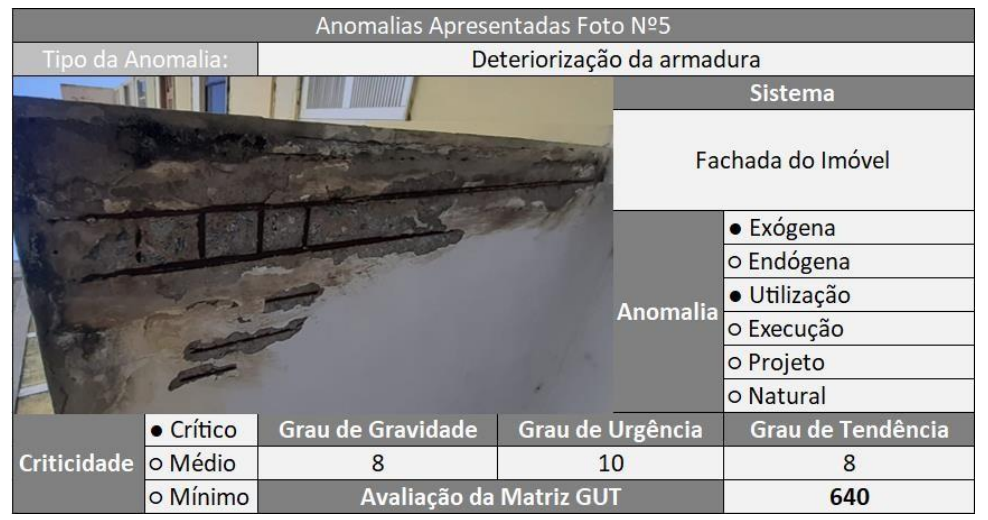

Figura 06: Avaliação das anomalias referente a deterioração de armaduras.

Fonte: Própria, 2019.

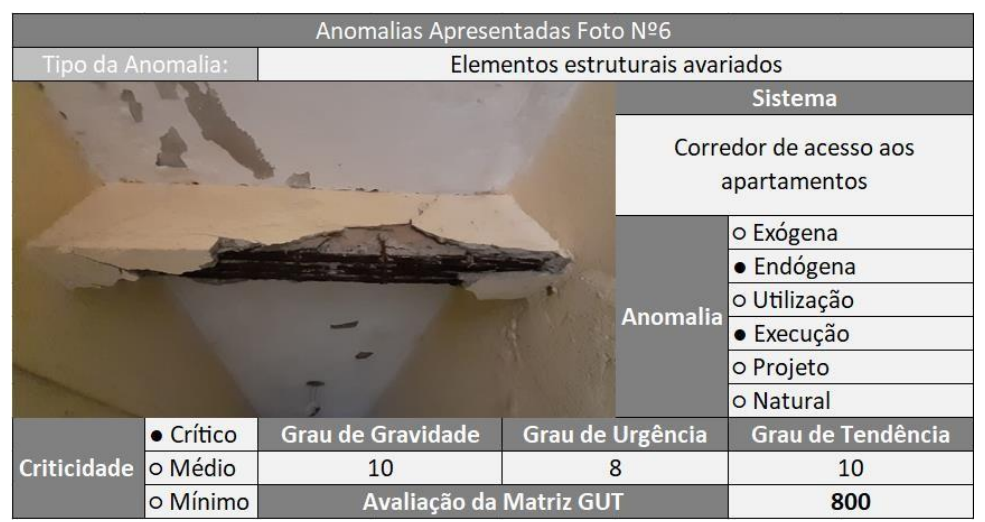

Figura 07: Avaliação dos elementos estruturais avariados.

Fonte: Própria, 2019.

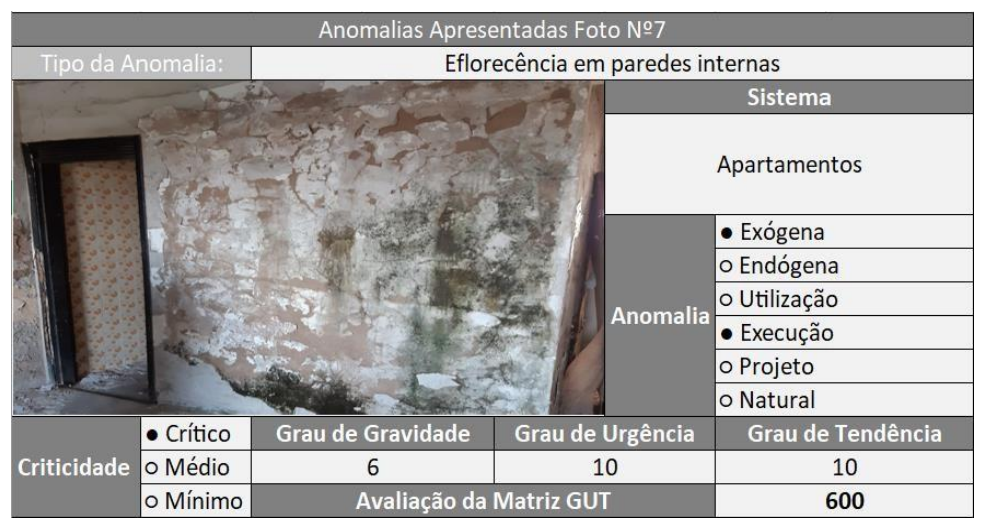

Figura 08: Avaliação das anomalias eflorescências.

Fonte: Própria, 2019.

Da avaliação da matriz GUT expostas nas Figuras 02 a 08 pode-se inferir, de maneira geral, que a edificação possui altos graus de gravidade, urgência e tendência, indicando que a estrutura é suscetível à colapso em curto prazo.

Os ensaios de ultrassom nas vigas em estudo apresentaram os dados expostos nos Gráficos 01 e 02 . A partir do gráfico de dispersão tempo vs distância foi possível calcular a VPU através da linha de tendência linear. 


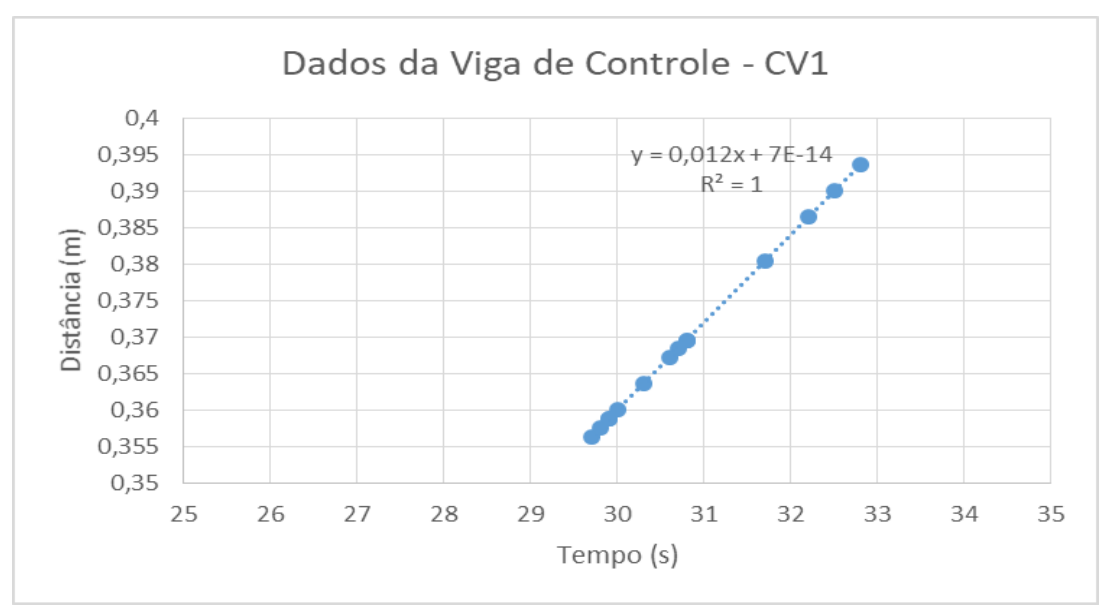

Gráfico 01: Dados dos ensaios de VPU na viga de controle (CV1).

Fonte: Própria, 2019.

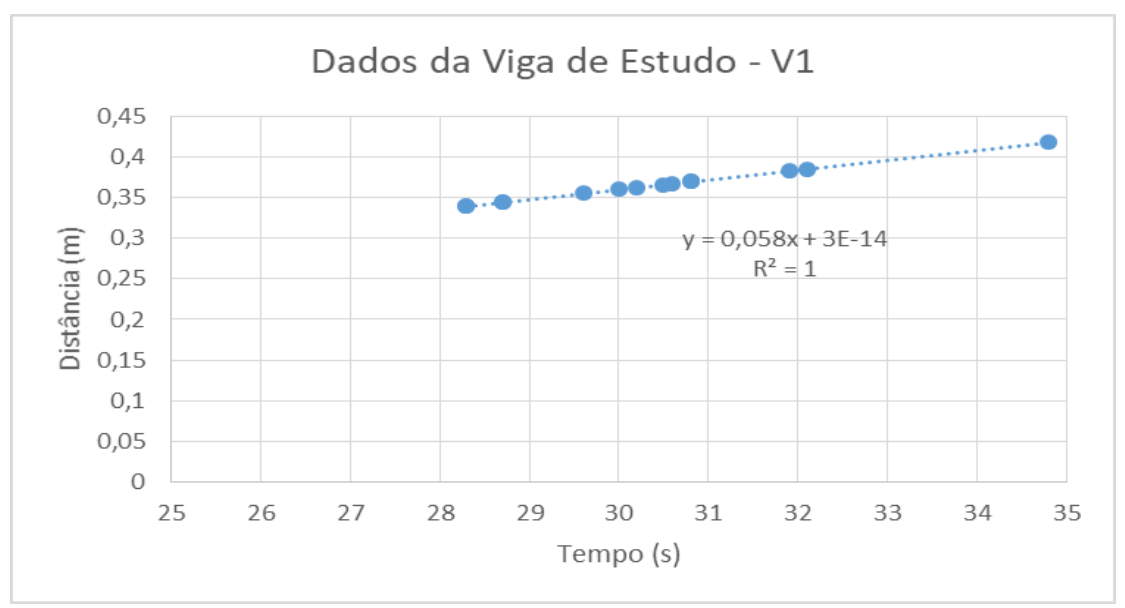

Gráfico 02: Dados dos ensaios de VPU na viga deteriorada (V1).

Fonte: Própria, 2019.

Por definição da ABNT NBR 8802:2019, o coeficiente angular da reta da linha de tendência é igual a VPU. Assim, para esse caso, a velocidade do pulso para a viga de controle (CV1) foi de $0,012 \mathrm{~m} / \mathrm{s}$ e da viga deteriorada em análise (V1) foi de $0,058 \mathrm{~m} / \mathrm{s}$, ou seja, uma velocidade de penetração 4,83 vezes maior para a viga V1. Outro dado importante a ser avaliado, e que não está previsto na norma, é o coeficiente de determinação $\left(R^{2}\right)$. Este coeficiente varia de 0 a 1 e relata quão o modelo está calibrado para explicar a correlação entre as variáveis analisadas, sendo 0 uma correlação muito baixa ou inexistente e 1 uma correlação muito alta. Para a análise das vigas o $\mathrm{R}^{2}$ foi igual a 1 tanto para a viga de controle como para a deteriorada.

Os resultados dos ensaios de VPU nos pilares em análise apresentaram os dados expostos nos Gráficos 03 e 04 . Os coeficientes de determinação $\left(\mathrm{R}^{2}\right)$ para o pilar de controle $(\mathrm{CP} 1)$ e o pilar deteriorado (P1) foram 0,87 e 0,83 , respectivamente. Importante ressaltar que tais valores se devem ao fato do ensaio ter sido realizado de forma semidireta, o que provoca a distorção por ressonância de ondas; no entanto, a magnitude dos coeficientes é aceitável. A VPU para o CP1 foi de $0,0074 \mathrm{~m} / \mathrm{s}$ e para o P1 foi de $0,0102 \mathrm{~m} / \mathrm{s}$, ou seja, o pilar deteriorado apresentou uma velocidade quase 1,4 vezes maior do que o pilar de controle. 


\section{СВРAT 2020 \\ concersso ans \\ DE 15 A 17 DE ABRIL | FORTALEZA - CE

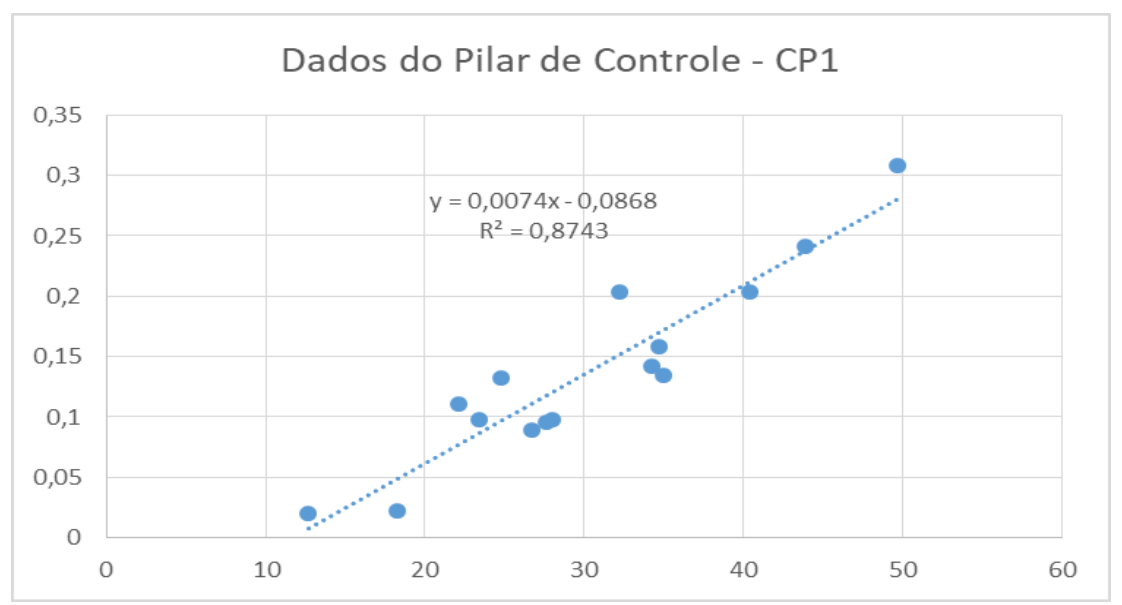

Gráfico 03: Dados dos ensaios de VPU no pilar de controle.

Fonte: Própria, 2019.

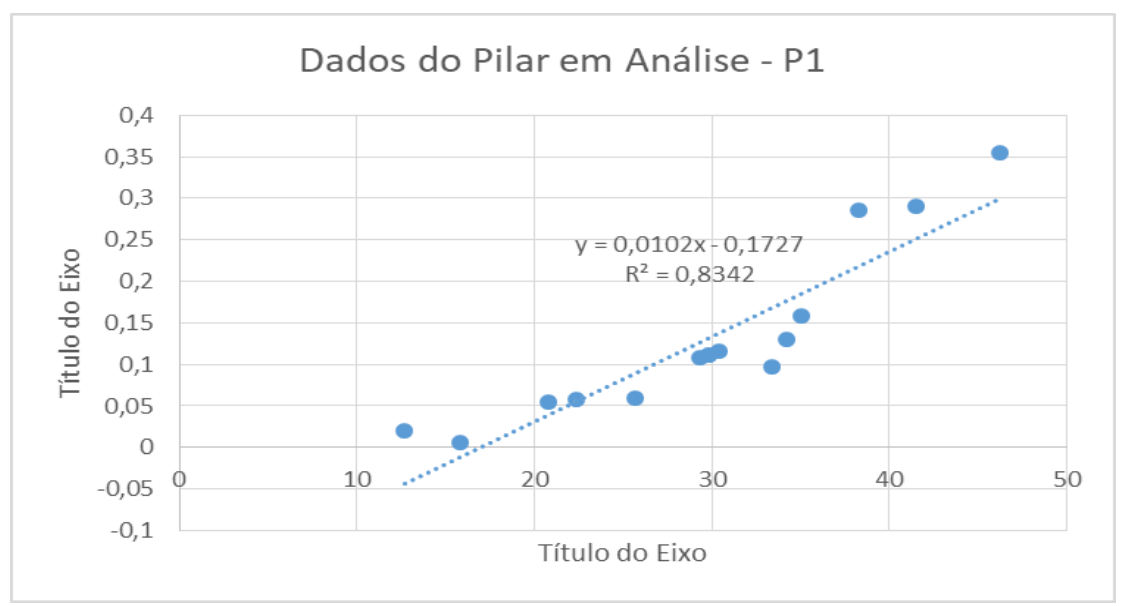

Gráfico 04: Dados dos ensaios de VPU no pilar deteriorado (P1).

Fonte: Própria, 2019.

No que diz respeito à carbonatação, foi realizado o ensaio em diversos elementos (vigas, lajes e pilares) de todos os pavimentos para verificar a incidência do fenômeno dada a região de tráfego intenso em que o imóvel está localizado. Constatou-se que, mesmo nos pavimentos mais altos, os elementos estruturais estavam seriamente carbonatados e, em alguns casos, o nível de corrosão das armaduras (provavelmente decorrente da carbonatação) era intenso, como pode ser verificado nas Figuras 09 a 11.

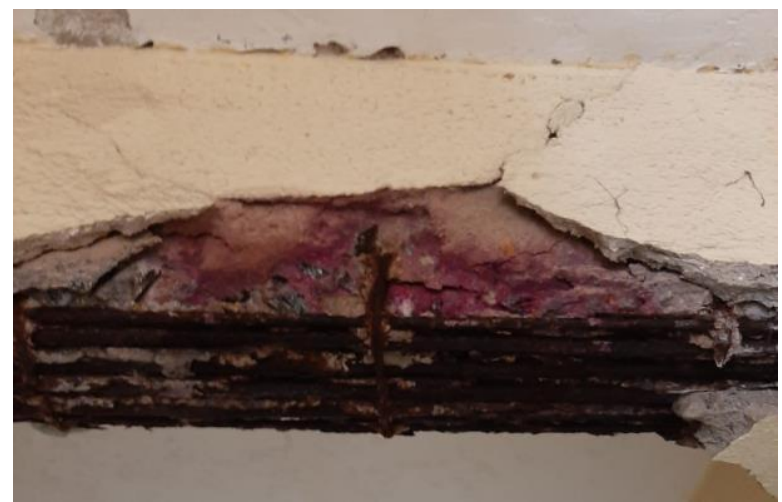

Figura 09: Ensaio de carbonatação em vigas. Fonte: Própria, 2019. 


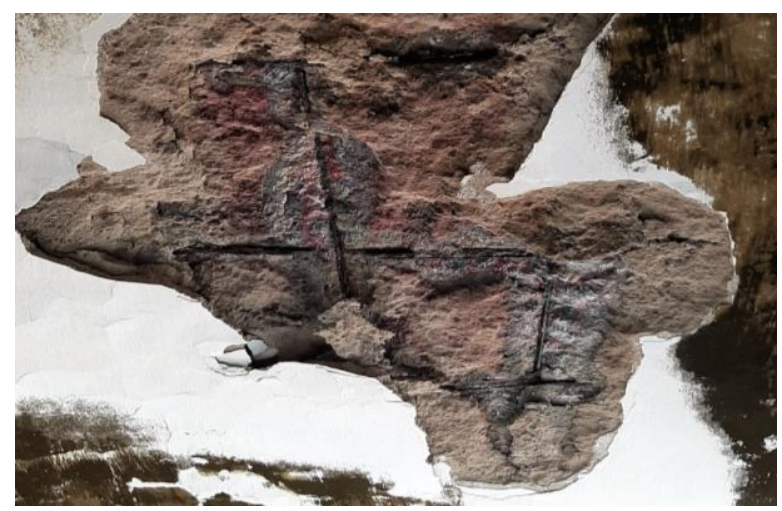

Figura 10: Ensaio de carbonatação em lajes. Fonte: Própria, 2019.

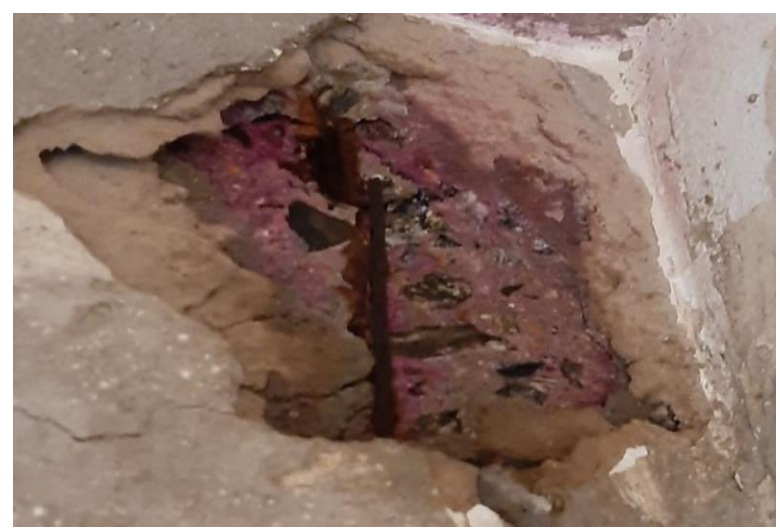

Figura 11: Ensaio de carbonatação em pilares. Fonte: Própria, 2019.

\section{CONCLUSÃO}

Os resultados obtidos das vistorias prediais, dos ensaios realizados e da matriz GUT alertam para o alto risco de colapso estrutural do imóvel, tendo em vista que foram pontuados 83 pontos críticos.

Constatou-se que diversas manifestações patológicas se intensificaram após a interdição. Identificou-se que a infiltração, atualmente, se encontra presente em quatro pavimentos, dada a existência de anomalias como eflorescência, bolor, desplacamento de revestimento em paredes e tetos, o que leva a supor que a caixa d'água não foi esvaziada após a interdição, agravando, portanto, tais anomalias. Também é preocupante a situação das lajes em balanço, que se apresentam com elevado grau de desplacamento do concreto de cobrimento devido a ação agressiva da umidade decorrente das chuvas.

Outro ponto crítico é o atual estado de deterioração dos pilares próximo ao poço do elevador, que apresentam fissuras de grandes dimensões e desplacamento do concreto de cobrimento ao longo de 5 pavimentos, deixando a armadura em alguns locais exposta ao meio e com altas taxas de corrosão.

Os ensaios de ultrassom mostraram que as vigas e pilares em análise perderam homogeneidade. A presença de umidade e fissuração são fatores deletérios que interferem na homogeneidade do concreto. Estes dados somados a existência de produtos carbonatados em vários pontos da estrutura pressupõe que está ocorrendo processo de lixiviação do concreto.

Por fim, entende-se que o edifício residencial e seu entorno precisa ser adequadamente isolado e que seja elaborado o projeto de demolição com a cautela do horário e tipo de demolição devido a localização do imóvel. Diante das tragédias recentes envolvendo imóveis antigos sem manutenções, a população da cidade anseia por uma resposta das autoridades. 


\section{REFERÊNCIAS BIBLIOGRÁFICAS}

ALVES, André Luiz Santos. Proposição de um método de caracterização de alvenarias de edificações históricas por meio de avaliação ultrassônica. 2017. Monografia (Bacharel em Engenharia Civil) Universidade Estadual Vale do Acaraú. Sobral. 2017.

Associação Brasileira de Engenharia e Consultoria Estrutural. CHECK LIST PARA VISTORIA DE EDIFICAÇÕES EM CONCRETO. Recife: ABECE, 2005.

ASSOCIAÇÃO BRASILEIRA DE NORMAS TÉCNICAS. NBR 8802 - Concreto endurecido - Determinação da velocidade de propagação de onda ultrassônica. Rio de Janeiro: ABNT, 2019.

CAMARGO, Renata Freitas de. Como fazer a Matriz GUT para a resolução de problemas? Conheça a Matriz de Prioridades. 2018. Disponível em: https://www.treasy.com.br/blog/matriz-gut/. Acesso em: 11 dez. 2019.

CARVALHO, E. M.; ALMEIDA, L. S. Check-list para inspeções prediais residenciais de múltiplos pavimentos: desenvolvimento e aplicação. 2017. Disponível em: https://ibape-nacional.com.br/biblioteca/wpcontent/uploads/2017/08/096.pdf. Acesso em: 10 out. 2019.

COSTA, A.S.; ZANCAN, E.C. Inspeção Predial: Estudo de caso de um edifício residencial, Criciúma - SC. Engenharia Civil, Criciúma, SC, 2012. Disponível em: . Acessado em: 23 de março de 2017.

FARIAS, D. A. S.; Diaguinóstico e Proposta de Intervenções Mitigadoras das Manifestações Patológicas da Orla Fluvial Altemar Dutra em Piranhas-AL. 2019. Monografia (Bacharel em Engenharia Civil) Universidade Federal de Alagoas. Delmiro Gouveia. 2019.

INSTITUTO BRASILEIRO DE AVALIAÇÕES E PERÍCIAS DE ENGENHARIA DE SÃO PAULO. Inspeção Predial: a saúde dos Edifícios, 2 ed. São Paulo: IBAPE/SP, 2017.

KAZMIERCZAK, C.S.; ZARA, L. Comparação entre metodologias utilizadas para a determinação da profundidade de carbonatação em argamassas. In: INTERNATIONAL CONGRESS ON HIGHPERFORMANCE CONCRETE, AND PERFORMANCE AND QUALITY OF CONCRETE STRUCTURES, Florianópolis, 1996. Proceedings. Florianópolis, 1996, p.402-413.

MEHTA. P. K; MONTEIRO P. J. M. Concreto: microestruturas, propriedades e materiais, 3 ed. São Paulo: IBRACON, 2008.

MEIRELES, M. Ferramentas administrativas para identificar, observar e analisar problemas. São Paulo: Art \& Ciência, 2001.

SOTILLE, M. Matriz GUT. 2014. Disponível em: https://dicaspmp.pmtech.com.br/matriz-gut-gravidade-urgenciae-tendencia/. Acesso em: 11 dez. 2019.

MOLIN, D.C.C.D.; PAU LETTI, C.; POSS AN,E. Carbonatação a celerada: Estado da arte das pesquisas no Brasil. Ambiente construído, Porto Alegre, v.7, nº 4, p.7-20,out/dez, 2007.

NEVILLE, A. M. Propriedades do concreto; Trad. GIAMUSSO, S. E. 2. ed. São Paulo, Pini, 1997.

TOKUDOME, N. Resultado de uma reação química afeta pH do material e pode reduzir a durabilidade da estrutura. Jun 2009. Acesso 28 Mar 2017

ROY, S.K.; BENG, P.K.; NORTHOOD, D.O. The carbonation of concrete structures in the tropical environment of Singapore and a comparision with published data for temperate climates. Magazine of Concrete Research, v.48, n.177, p.292-300. Dec. 1993. 